\title{
Summary Report of the Workshop on the Interactions of Climate and Energy
}

\author{
J. B. Knox ${ }^{1}$, H. Moses ${ }^{2}$, and M. C. MacCracken ${ }^{1}$
}

\begin{abstract}
The joint Industry/DOE Workshop on the Interactions of Climate and Energy was designed to bring the providers of climate information and services together with users and representatives of the oil, gas, coal, and electric utility sectors of the U.S. energy industry. Primary discussion topics included current uses of climate data, the perceived impacts of climatic anomalies on the energy sector, ways to improve the uses of climate data, and recommendations for future research by the climate community. This opportunity for such interaction generated a universal agreement among the participants that more frequent exchanges between the providers and users of climate information be planned and that better communication between the providers and users of climate data and services be established.

The workshop proceedings, which is being published by the Department of Energy, presents studies on the application of existing data to the diagnosis of the climatic component in energy supply and demand and the short-term prediction of regional scale energy requirements. Staff members of the National Oceanic and Atmospheric Administration's (NOAA) National Climate Data Center (NCDC) and Climate Analysis Center (CAC) review the currently available climate data and services. Four panel reports identify and enumerate the impacts of climate on each of the segments of the energy industry and offer recommendations for improvements, further research, and, in some cases, concepts for practical demonstrations of immediate potential value to the pertinent energy sector.

The panel findings and the presentations of the invited speakers contain several common themes: the need for improved data formats, the significant potential benefits of increased lead time for the seasonal climate forecast, and the necessity for improved accuracy in the forecasts of monthly and seasonal means and extremes of temperature and precipitation. Workshop participants fully recognized the difficulty of making "real" progress on some of these commonly stated objectives; however, they also recognized that the benefits of striving to achieve these goals may, indeed, be sufficiently great to justify the quest for progress through focused research efforts.
\end{abstract}

\section{Introduction}

The primary goal of the 1983 joint Industry/DOE Workshop on the Interactions of Climate and Energy was to bring together the providers of climate and weather information and services with users and representatives of the oil, gas, coal,

\footnotetext{
${ }^{1}$ Lawrence Livermore National Laboratory, University of California, Livermore, CA 94550.

${ }^{2}$ U.S. Department of Energy, Washington, DC 20545.

(c) 1985 American Meteorological Society
}

and electric utility sectors of the U.S. energy industry. Specific objectives of the workshop included the development of greater awareness in the energy industry of the types of climate data available for addressing current climate impact issues, the identification of practical improvements in climate data, and the development of recommendations for future applied research by the climate community. The workshop was held 6-8 June 1983 at the Cliffside Motor Inn, Harpers Ferry, West Virginia.

Professor H. Landsberg, Professor Emeritus of the University of Maryland, College Park, gave the opening keynote address, "Overview: Climate and Energy Interactions," in which he presented a multifaceted montage of challenges and discussed what he perceived to be three important current issues on the climate/energy interface: climate as it affects conservation measures, climate as it impacts on system operations by way of extremes, and the use of climate information in the development of renewable resources, such as solar, wind, and hydroelectric power.*

Dr. Landsberg identified the key issue as the proper estimation of extremes from the climatic record, for it is the extremes that carry the real impacts to system operations and affect system design. The climate signal available to estimate these extremes is "the statistical collection of all weather events over a long interval of time, usually measured in terms of several decades." Dr. Landsberg suggested that, depending on potential use of the information, the normal of the most recent decade might well be more useful in estimating extremes than that of the much longer period due to the presence of low-frequency variations. He warned all users that the combination of short-and long-term climatic variations serves to remind us that there is no such thing as "normal climate."

Man's failure to understand the earth's climate/weather system or to acquire suitable data has led to specific instances of design flaws or failures. Examples cited include the failure of designed bridges in high winds, loss of efficiency of the Aswan Dam due to improper consideration of the hydrologic cycle, and the fallacy of tall stacks as a solution to air pollution problems. The implied question for the conferees was what failures are being born by the current neglect of climate impacts and of the possibilities for the improved use of available data.

\footnotetext{
*This last topic, while very important, was specifically excluded from major consideration at this workshop.
} 
To address the many issues raised, the workshop was divided into four sections, representing the oil, gas, coal, and electric utilities. In plenary session, invited papers describing the current use of weather and climate data and forecasts in the respective energy sector were presented by representatives of both the energy industry and the meteorological community. Subsequent to the plenary sessions, panels representing each energy sector were formed to more thoroughly discuss the current use of data and the potential for future improvements in energy system efficiency by use of weather and climate data and forecasts.

The panels were chaired, in most part, by a senior member from the relevant energy sector and assigned a rapporteur who prepared the summary of the panel's findings:

\section{OIL}

Mr. Ronald Jones, Panel Chair

American Petroleum Institute

Washington, DC 20037

Dr. William E. Riebsame, Rapporteur

University of Wyoming and

National Climate Program Office

Laramie, WY 82071

Mr. David J. H. Peters, Rapporteur

CONOCO Corporation

Houston, TX 77252

\section{GAS}

Dr. John A. Laurmann, Panel Chair

Gas Research Institute

Chicago, IL 60631

Mr. Ken Hadeen, Rapporteur

NOAA/NESDIS/AISC

Washington, DC 20235

\section{$C O A L$}

Mr. John Wilson, Panel Chair

Morgantown Energy Technology Center

Morgantown, WV 26505

Mr. Bernard Dethier, Rapporteur

National Climate Program Office

Rockville, MD 20852

\section{ELECTRIC UTILITY}

Dr. Ralph Rotty, Panel Chair

Institute of Energy Analysis

Oak Ridge, TN 37830

Dr. Wayne M. Wendland, Rapporteur

Illinois State Water Survey

Champaign, IL 61820

Workshop participants recognized that after years of evolution and very substantial investments, the U.S. energy industry is resilient, reliable, and reasonably protected from impacts by most climatic a nomalies, the exceptions being the most extreme seasons or weather events. These characteristics, uniquely interpreted for each energy sector, provided an important framework for the development of recommenda- tions by each panel. Energy systems were more sensitive to climate impacts in situations with long lead times and when distances between fuel production facilities and energy generation and use are long. Electric utility systems, however, with near instantaneous energy delivery, showed greater sensitivity to severe weather impacts. In the 1980 s, regulatory requirements, particularly in setting rates, have also played an important role in determining the use of climate information for estimating the climate/weather contribution to demand. Some of the present uses of data led to suggestions for improved data formats and greater interchange between the providers of data and the user.

These concepts and themes emerged in the planning meetings for the workshop and were consistent with, but perhaps more constructively expressed, the prior findings of a JASON study of 1980 (H. Abarbanal et al., Regional-Seasonal Weather Forecasting, JASON Technical Report JSR 80-05, 1983). That study concluded that, despite improved computers and an understanding of the earth's climate system, seasonal climate forecasts are too imprecise and too limited in skill to be useful in guiding fuel planning or fuel allocation policies.

To develop a perspective on the potential for use of monthly and seasonal forecasts, presentations on the promise and problems of climate forecasts were given by Dr. Jerome Namias (Scripps Institution of Oceanography, La Jolla, California) and by Dr. Donald Gilman (Chief, Prediction Branch, Climate Analysis Center, NOAA, Washington, D.C.). The limitations of the current seasonal climate forecasts notwithstanding, the participants recognized the value that would accrue from increased accuracy, especially if available with longer lead times. Some felt that, if feasible, emphasis should be placed on the prediction of extremes, rather than means, since the energy sector is highly resilient when faced with small anomalies. The participants of the workshop, and specifically the providers of the climate information, held divergent views on the prospects of progress on these matters, which must remain topics for future research.

The 1983 workshop/dialogue process also identified several emerging areas where climate da ta can be valuably used. These included, improved climate data for evaluating the meteorological-climate component in fuel demand for ratesetting (gas sector), regulation of pipelines and storage by regulatory bodies (gas-FERC), high spatial resolution climatology of severe weather (coal), and climatology of terrain-controlled sites for reclamation of surface mining areas (coal).

\section{Prospects for improved long-range forecasting}

Dr. Gilman's invited address, entitled "Long-Range Forecasting: The Present and the Future," reminded the participants that there is no quantitative theory for long-range weather forecasting in a "physicist's sense," but that longrange forecasting is at present an empirical art. As such, it uses a mix of procedures, such as statistical methods, ana- 
logs, and physical reasoning, to determine when not to simply use climatological persistence. He viewed the current outlook for long-range climate forecasting as optimistic, citing several reasons: computers have become more powerful and faster, more testing can be performed on models and on schemes used for longer range forecasting than was possible only a few years ago, and different kinds of skilled people have become interested in climate predictions. The new talents are being applied to the problem by modelers, theoreticians, diagnosticians, and computational experimentalists.

There has also been a substantial increase in interest in long-range forecasting internationally. Specifically, a consortium of European countries has cooperated in establishing the European Centre for Medium Range Weather Forecasting, and their successes to date should be viewed as precursors of better things to come. Satellite systems also provide information to form data bases that may be used to test climate hypotheses or theories. A final reason for optimism is the increased frequency of recent and unusual climate anomalies, which have attracted attention beyond the climate research community. Therefore, the problem of climatic perturbations has achieved substantial visibility that has resulted in the potential for increased budgetary support.

\section{a. Monthly forecasting}

An important step in improving monthly forecasts will be the increased use of dynamical prediction models at a number of research centers. In general, the models used are the biggest and best available. Interest extends to a number of federal agencies and also to European scientists. The use of these models is not merely to provide a forecast, but also to provide information on the degree of predictability associated with the forecast. But despite the availability of such models, Gilman believes progress will be difficult in forecasting temperature variations within the month and in forecasting precipitation.

One of the most important aspects of forecasting is that of extremes. Gilman believes that projections of progress in forecasting monthly extremes are speculative and that the prospects for forecasting extreme weather events in a given subperiod are even more speculative. Gilman gave the workshop little cause for optimism for the forecasting of extreme conditions. He was also very pessimistic regarding the problem of increasing the lead time of monthly climate forecasts. Reliable forecasting with lead times (the interval between the issuance of the forecast and the beginning of the forecast period) of several months he considered unlikely in the foreseeable future.

\section{b. Seasonal forecasting}

Gilman believes more optimism is justified concerning the success of seasonal forecasting, because the approaches to seasonal forecasting are quite different from monthly forecasting. In seasonal forecasting, the initial conditions assume less importance; the factors of greatest importance are seasurface temperature, soil moisture, and the presence or absence of snow or ice. While there may also be a dependence of seasonal forecasting on cyclic phenomena, it is not yet clear how to make use of such information. The quasi-biennial os- cillation, for example, can be seen clearly in some records, and on the other hand, it does not show up well in others.

Cyclic patterns or patterns related to the El Niño/Southern Oscillation phenomenon that is perhaps the biggest globalscale organized fluctuation in the atmosphere, with a time scale of years, may be of use, however. When this phenomenon is strong, Gilman believes chances are improved for increased skill in seasonal climate forecasts.

Concerning the forecasting of seasonal extremes, Gilman reflected ambivalence. Certain kinds of extreme events may provide a clue to their predictability. If progress is to be made, he believes it would probably be associated with an increased understanding of the El Niño/Southern Oscillation phenomenon.

On the question of longer lead times, Gilman was, again, quite pessimistic. The Climate Analysis Center and the Scripps Institution of Oceanography are both investigating methods for increasing the lead time of seasonal climate forecasts, but they do not expect immediate improvements in this area.

\section{c. The future of long-range forecasting}

Dr. Jerome Namias, who had just been elected to the American Academy of Arts and Sciences, added his perceptions and experience to the discussions of the future of long-range forecasting. He expressed a considerably more optimistic viewpoint than Gilman in regard to the possibility of forecasting extreme climatic conditions and the possibility of increasing the lead time from the issuance of the forecast to the start of the forecast period.

His optimism for improvements in the ability to forecast extremes is based on the impression that "extreme events cast their shadows well before they take place," for example, the cold winter of $1976-77$ or the warm winter of 1982-83. In fact, Namias saw hopeful signs on the horizon that forecasters need not be limited to making predictions only one season in advance. While these impressions are intuitive, and are, of course, devoid of evidence of proof, he believes it is becoming progressively more clear that climate fluctuations are not merely noise, and further, that more than just the characteristics of the atmosphere system influence the seasonal climate.

Additional significant influences include sea-surface temperatures, soil characteristics, particularly soil moisture, and snow and ice fields, especially when they occur over uncommon areas or at unusual times. Namias stated that "such anomalies can, for example, alter surface reflectivity, which in turn can alter the storm path that frequently replenishes the snow." Some of these anomalies have long time constants, such as the well-mixed layer of the ocean, which retains its thermal signature to a few hundred meters because of the water's high heat capacity.

Namias believes that understanding and accounting for the interaction between the atmosphere, ocean, and land surface is, indeed, the hope for long-range forecasting. He suspects that the receptivity of the atmosphere to certain types of patterns does not extend to only a season in advance but might be foreshadowed a year or two in advance. This may be explained by the slowness of the motions of Pacific Ocean currents and the tendency of sea-surface temperature anom- 
alies to be preserved. Thus, there is a possibility that if we account for all these processes and accept help from the numerical modelers and dynamicists as well, he believes we will be able to progress to the point of making skillful forecasts of climate fluctuations a year or two in advance.

On the outlook for long-range climate forecasts, the keynote speakers produced divergent impressions: one a message of optimism, and one a message of pessimism on the issues of practical concern to users; namely, the ability to predict extremes and the prospects for increased lead time for the climate forecasts. Only time will resolve the question of whether research can develop the capability to detect the precursor patterns of forthcoming anomalies-the shadow of events-that might make these practical needs addressable.

\section{Currently available climate data and services}

Staff members of NCDC and CAC, both organizations of NOAA, presented descriptions of the currently available climate data and the kinds of services and products included in published reports. Their presentations were made in response to requests from the energy industry for an up-todate description of these activities.

\section{a. Data available from NCDC}

The mission of NCDC is to archive and publish climatological information describing the climate of the U.S. Two types of climatological information were discussed: a) hourly observations, and b) daily and monthly data.

NCDC receives by mail hourly data from over 1600 U.S. stations. The data from 280 of these stations are placed on magnetic tape for transfer to their mainframe computer. Careful quality control is applied to these data. For observations prior to 1965 , all 24 measurements per day have been keyed onto data cards. Since 1965, only eight observations per day (one every three hours) for each station have been keyed. Then after July 1981, the National Weather Service reverted to the keying of all of the hourly data. Manuscript copies of the hourly observations are placed on microfiche cards (one card per station per month). The hourly observations generally consist of values for temperature, dewpoint, cloud cover, visibility, pressure, wind speed, direction, and the observer's comments, where appropriate. Hourly data along with daily and monthly values are published monthly in NOAA's Local Climatological Data publication for 282 stations. This publication is a vailable for some stations as far back as 1949.

In addition to the hourly observations, NCDC receives forms containing daily weather information from some 7800 stations commonly known as cooperative (COOP) stations. This information consists of daily maximum and minimum temperatures, temperature at time of observation, total daily precipitation, and information on special weather conditions. For a few hundred stations, measurements of evaporation and soil temperature are also transmitted. These data are grouped by state and placed on tape. Some of these records date back to 1876; original records a re filmed in 5-year groups (such as 1950-1954) and archived. The daily and monthly summarized data are published by state and appear monthly in the NOAA publication called Climatological Data, which is available on a subscription basis.

\section{b. Products available from $C A C$}

The Climate Analysis Center within the National Weather Service is responsible for the generation and dissemination of long-range forecasts and current data products. Both are derived from continuously updated meteorological data from tens of thousands of surface reports, about 1600 upperair observations, aircraft measurements, and satellite information.

CAC's Prediction Branch prepares and publishes, semimonthly, forecasts of 30-day average temperature, total precipitation, mean upper-air circulation, prevailing storm tracks, and high pressure centers. On a monthly basis, it also publishes 90-day forecasts of average temperature and total precipitation. These are published in NOAA's Monthly and Seasonal Weather Outlook, available by subscription.

The Analysis and Information Branch develops and produces quality controlled climate data sets. The vast number of global surface and upper air stations is used for this purpose. Derived products such as heating and cooling degree days are also produced. Some of these appear in the NOAA publications Weekly Weather and Crop Bulletin, also available by subscription, and the Weekly Climate Bulletin, of more limited distribution. Other derived products such as the Temperature-Humidity Index, or the Heat-Wave Index, or public a wareness information on global anomalies events are also prepared. CAC data sets and products are available promptly through a dial-up minicomputer.

\section{Examples of current use of climate data by the energy industry}

Over the years, the uses of climate data by the energy industry have evolved along with the sophistication of the industry and with the requirements of various state and federal agencies. As previously mentioned, modern uses of climate data in this setting include the isolation of the climate/weather component of the load-demand for purposes of rate setting, the short-term regional customer demand for fuel oil, and government advisories in regard to pipeline supplies and the storage of natural gas. Regression equations have been developed for use in making both predictive and diagnostic estimates of the load demand based on measured or prescribed values of the independent variables. The regression models are also used with historical data to determine the relative contribution of each of the independent variables to the load demand. Table 1 shows the independent and dependent variables presented in the four papers dealing with modern applications of climate data by each sector of the energy industry.

A group at the Boston Edison Electric Co. has used regression techniques to determine the impact of weather variables on the electric load. By removing the contribution to load from weather effects, it is possible to determine the influence of other factors, such as the price of fuel or population 
TABLE 1. The independent and dependent variables used in each of the four papers using a regression approach to relate energy and weather/climate factors.

\begin{tabular}{|c|c|c|}
\hline \multirow[b]{2}{*}{ Investigator } & \multicolumn{2}{|r|}{ Variables } \\
\hline & Dependent & Independent \\
\hline \multirow[t]{7}{*}{ Rodekohr } & Oil demand for a & Price \\
\hline & given month & Real disposable income \\
\hline & & Heating-degree days (HDD) \\
\hline & & Population-weighted HDD \\
\hline & & Oil consumption (weighted) \\
\hline & & Natural gas curtailment variable \\
\hline & & Previous month's oil consumption \\
\hline \multirow{9}{*}{$\begin{array}{l}\text { Ison, Piotroski, } \\
\text { and Mogolesko }\end{array}$} & Electric load & Temperature \\
\hline & & Relative humidity \\
\hline & & Temperature-humidity index \\
\hline & & Wind chill \\
\hline & & Sky cover \\
\hline & & Hour \\
\hline & & Windspeed \\
\hline & & Heating, cooling, or intermediate season \\
\hline & & Weekend/holiday vs. weekday \\
\hline \multirow{4}{*}{$\begin{array}{l}\text { Warren, LeDuc } \\
\text { and Hock }\end{array}$} & Energy consumed & Heating-degree days of current season \\
\hline & & $\begin{array}{l}\text { Price index (energy per unit price) of } \\
\text { previous heating season }\end{array}$ \\
\hline & & Monthly average heating bill \\
\hline & & Actual price \\
\hline \multirow{19}{*}{ Reiter } & Power generation & Month \\
\hline & & Day of week \\
\hline & & Time of day \\
\hline & & Weather: \\
\hline & & temperature \\
\hline & & minimum temperature \\
\hline & & maximum temperature \\
\hline & & previous hour temperature \\
\hline & & $\begin{array}{l}\text { relative humidity } \\
\text { wind }\end{array}$ \\
\hline & & Special conditions: \\
\hline & & rain \\
\hline & & $\begin{array}{l}\text { thunderstorms } \\
\text { sky coverage }\end{array}$ \\
\hline & & Yesterday's information \\
\hline & & high temperature \\
\hline & & load at 24 hours ago \\
\hline & & Temperature \\
\hline & Air conditioning & Wet-bulb temperature \\
\hline & load & Solar radiation \\
\hline & & Windspeed \\
\hline
\end{tabular}

growth. The authors refer to this process as "weather normalization." Data have been stratified by three classes of temperature, by each of the 24 hours, and by weekday and weekend, thus providing $3 \times 24 \times 2$, or 144 , classes. A separate regression equation was developed for each combination. In general, the predicted values of load varied by only a few percent of the actual load.

The paper presented by Rodekohr of DOE/EIA showed that an oil-consumption-weighted degree-day was preferable to a population-weighted degree-day and that significantly different results were obtained with each choice. As seen in Table 1, his analysis used the demand for heating oil as the dependent variable and the price of heating oil, real disposable income, and oil-consumption-weighted heatingdegree day as the independent variables.

Another paper by Warren, LeDuc, and Hock of NOAA dealt with determining the monthly average heating bill, which, of course, is directly related to the energy consumed.
This group based its evaluation on a customer-weighted heating-degree day and an economic factor.

A fourth paper by Reiter used a regression technique to determine: a) prediction of seasonal demand variability; b) optimization of electric generator use schedules; and c) analysis of loads for large buildings. As seen from Table 1, this analysis uses direct weather variables, temporal variables, and lagged variables, such as the load 24 hours earlier, or yesterday's maximum temperature.

\section{Panel findings and recommendations}

The attendees of the workshop were divided into four panels, each representing a separate sector of the U.S. energy industry: oil, gas, coal, and electric utilities. Each panel was asked 
TABLE 2. Summary of the components that have climate sensitivity.

\begin{tabular}{llllc}
\hline \hline & Oil & Gas & Coal & Electric \\
\hline Exploration & $\mathrm{X}$ & $\mathrm{X}$ & & \\
Site selection & & & $\mathrm{X}$ & $\mathrm{X}$ \\
Extraction & $\mathrm{X}$ & $\mathrm{X}$ & $\mathrm{X}$ & \\
Processing & $\mathrm{X}$ & $\mathrm{X}$ & $\mathrm{X}$ & $\mathrm{X}$ \\
$\begin{array}{l}\text { Transportation } \\
\quad \text { (distribution) }\end{array}$ & $\mathrm{X}$ & $\mathrm{X}$ & $\mathrm{X}$ & \\
Storage & $\mathrm{X}$ & $\mathrm{X}$ & $\mathrm{X}$ & \\
Utilization & $\mathrm{X}$ & $\mathrm{X}$ & $\mathrm{X}$ & $\mathrm{X}$ \\
$\quad$ (coverage & & & & \\
$\quad$ demand) & & $\mathrm{X}$ & & $\mathrm{X}$ \\
$\begin{array}{l}\text { Peaksindemand } \\
\text { Reclamation }\end{array}$ & & $\mathrm{X}$ & $\mathrm{X}$ \\
Rate setting & & $\mathrm{X}$ & & \\
\hline
\end{tabular}

to delineate the current uses of climate data in its energy sector, to enumerate the relevant climate and weather impacts, to identify ways to improve climate data bases to better suit its needs, and to make recommendations for future research by the climate community.

In general, there are many components or activities that when linked together contribute to an energy system: exploration, site selection, extraction, processing, transportation, storage, utilization, peaks in demand, reclamation, and rate setting. Not all of these components are common to the four energy sectors; but in the aggregate of systems, these components emerge, and each has a different sensitivity to climatic impacts, varying from a significant sensitivity to having no sensitivity at all. Table 2 summarizes the components that have a noticeable climate sensitivity. With this perspective on the climate-sensitive activities of each energy sector, we present, in brief, the findings of the panels.

\section{a. Oil}

In the oil (or petroleum) industry, climate/weather conditions impact the activities of exploration, extraction (production), transportation, refining, and demand (see Table 2). These impacts are nowhere more graphically illustrated than in coastal or offshore activities, where tropical storms and their associated wave surges are of greatest concern. The transportation impacts of climate are generally fewer than in the other activity sectors of the industry, since about $80 \%$ of the oil is transported by pipeline. For the other $20 \%$, oceangoing tankers, oil-carrying vessels on domestic waterways, and truckers are impacted by extreme weather conditions. The most climate/weather-sensitive part of the industry is refining, where seasonal forecasts of temperature and precipitation with sufficient lead time, presumably at least one season, would be most helpful for management of crude and heating oil reserves, determining refining mixtures, and planning for an adequate water supply for cooling and processing.

Regional oil shortages due to climate extremes can be moderated somewhat, since the industry has a 3- to 6-week storage capacity, in addition to flexible delivery modes. A rather large cost is imposed to develop this reserve, however, especially in the late summer and fall in anticipation of winter demand. At present, no use is being made of CAC fore- casts to adjust reserve requirements upward or downward; instead provision is typically made to provide reserves for a constant high fraction (e.g., 90\%) of the heating-degree day requirement expected based on use of the 30-year climatic normal.

Several climate-related priorities were identified for the petroleum industry (see Table 3 ). To help in offshore exploration and production activities, the acquisition of improved baseline climatic data is needed, particularly in remote areas such as the Arctic, the North Sea, or the South Pacific. Improved climate data and prediction techniques focused on improving lead times for estimating seasonal demand, particularly in extreme years, would be most constructive and helpful. A review of relevant case studies focused on these needs was recommended by the petroleum panel. At present, little use is made of seasonal climate forecasts for determining refinery mixes or anticipating subsequent season reserve levels because of the inability to meet the requirement for increased lead time and doubts generated by usual measures of forecast accuracy. Better use of probabilistic forecast concepts was suggested, because the large reserve capacity of the oil sector allows the potential for economic benefits (e.g., lowering heating oil reserves in predicted warm years) without significant risk. Finally, and as with other panels, a better working relation between the providers of climate information and users was strongly recommended.

\section{b. Gas}

Climate and weather impact the gas industry in a number of ways (see Table 4). The peak demand for gas space heating is sensitively controlled by the ambient temperature, its extreme values, and, to a lesser degree, associated wind conditions. If the temperature falls too low, then the use of gas will be high. As a result, a sizable fraction of the gas is drawn from the pipeline or from storage, with the attendant drop in pressure perhaps interfering with delivery. An unusually warm winter may cause a natural-gas glut and high storage costs due to carryover. Rate setting and long-range construction plans also depend on climate; historical climate data are used for this purpose.

The recommendations of this group, as with most of the others, dealt with the improvement of data, forecasts, and communications, and suggestions for enhanced service from NOAA and the National Climate Program Office (see Table 4). The need for improved representativeness of data was stressed. For example, the errors in estimating gas demand arising from the use of rural airport meteorological data to estimate or represent the city environment were pointed out. The group recommended that temperature measurements for this intended purpose be made near the "center of gravity" of population centers. Improved, user-friendly access via computer to the NCDC climate data base was cited as a much-needed improvement for the gas industry.

Improved prediction is sorely needed with respect to forecasting weather extremes and extreme seasonal anomalies leading to high gas demand. It was recomended that studies be carried out to identify those large-scale anomalies that lend themselves to improved prediction. It was suggested that the efforts of the National Climatic Program be further 
TABLE 3. Summary of findings of the Panel on Climate and the Oil Industry.*

\begin{tabular}{|c|c|}
\hline List of impacts & $\begin{array}{l}\text { Identification of needs and } \\
\text { recommendations }\end{array}$ \\
\hline $\begin{array}{l}\text { Exploration } \\
\text { Weather and climate can adversely affect } \\
\text { access to sites and timing of exploration }\end{array}$ & $\begin{array}{l}\text { More relevant climatic data bases via } \\
\text { satellite for use in exploration in } \\
\text { remote areas in the Arctic, North } \\
\text { Sea, and South Pacific }\end{array}$ \\
\hline $\begin{array}{l}\text { Extraction-offshore } \\
\text { Tropical storms } \\
\text { Wave heights and surges } \\
\text { Winds } \\
\text { Ocean tides and currents }\end{array}$ & $\begin{array}{l}\text { Better forecasts of tropical storms and } \\
\text { surges }\end{array}$ \\
\hline $\begin{array}{l}\text { Processing-refining } \\
\text { Refinery mixture is dependent on expected } \\
\text { temperature for coming season } \\
\text { Water supply for cooling and processing } \\
\text { is dependent on rainfall }\end{array}$ & $\begin{array}{l}\text { Increased lead time of seasonal } \\
\text { forecasts }\end{array}$ \\
\hline $\begin{array}{l}\text { Transportation } \\
\text { Delivery by truck, ship, and waterway ( } 20 \%) \\
\text { is delayed because of snow, ice, and } \\
\text { extreme weather }\end{array}$ & Better use of probabilistic forecasts \\
\hline $\begin{array}{l}\text { Utilization (demand) } \\
\text { Heating oil demand depends on temperature } \\
\text { Agricultural demand depends on spring } \\
\text { weather } \\
\text { Vehicular demand for gasoline is climate- } \\
\text { dependent }\end{array}$ & $\begin{array}{l}\text { Improved techniques for predicting } \\
\text { extreme climatic conditions }\end{array}$ \\
\hline
\end{tabular}

*The content of Table 3 is derived from "Summary Report of the Panel on Climate and the Oil Industry," R. Jones, panel chair, and W. E., Riebsame, and D. Peters, rapporteurs.

TABLE 4. Summary of findings of the Panel on Climate and the Gas Industry.*

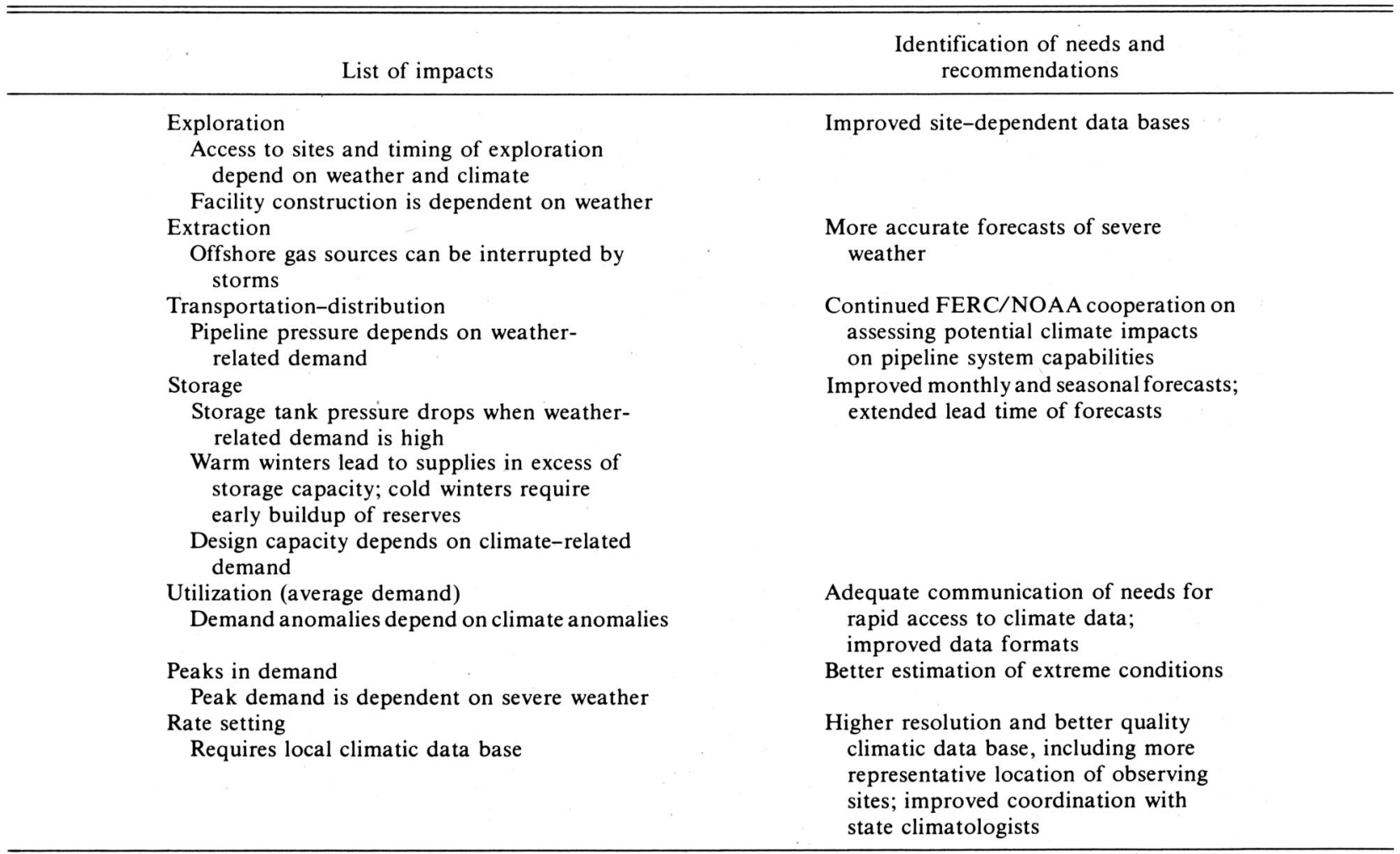

*The content of Table 4 is derived from "Summary Report of the Panel on Climate and the Gas Industry," J. A. Laurmann, panel chair, and K. H. Hadeen, rapporteur. 
TABle 5. Summary of findings of the Panel on Climate and the Coal Industry.*

\begin{tabular}{|c|c|}
\hline List of impacts & $\begin{array}{l}\text { Identification of needs and } \\
\text { recommendations }\end{array}$ \\
\hline $\begin{array}{l}\text { Site selection } \\
\text { Development of climatic information for } \\
\text { permitting }\end{array}$ & High resolution climatic data bases \\
\hline $\begin{array}{l}\text { Extraction-underground mining } \\
\text { Release of inflammable methane }\left(\mathrm{CH}_{4}\right) \text { in } \\
\text { mines from sharp pressure drops } \\
\text { Increase in probability of mine explosions } \\
\text { from low relative humidities, particularly } \\
\text { in winter } \\
\text { Roof collapse from low relative humidity } \\
\text { Dangerous icicle formation that might allow } \\
\text { icicles to fall to bottom of mine shaft } \\
\text { Ice and freezing effects on conveyor belts } \\
\text { Loss of life and equipment from flooding } \\
\text { in mine shaft }\end{array}$ & $\begin{array}{l}\text { Pilot or demonstration project to } \\
\text { determine short-range forecast needs } \\
\text { for surface mining }\end{array}$ \\
\hline $\begin{array}{l}\text { Extraction-surface mining } \\
\text { Equipment breakage and malfunction due to } \\
\text { ice } \\
\text { Ineffective backfill due to snow and ice } \\
\text { Muddy roads interfering with coal transport } \\
\text { Fugitive dust due to prolonged lack of } \\
\text { precipitation and low humidity } \\
\text { Flooding, erosion, and rotting due to } \\
\text { excessive precipitation }\end{array}$ & $\begin{array}{l}\text { Better climatologies of severe weather } \\
\text { phenomena }\end{array}$ \\
\hline $\begin{array}{l}\text { Transportation } \\
\text { Freezing of lakes and rivers interfering } \\
\text { with transport by barges } \\
\text { Freezing of coal in railroad cars } \\
\text { Storage } \\
\text { Freezing of coal in storage piles } \\
\text { Effect on coal quality due to wetness from } \\
\text { excessive precipitation }\end{array}$ & $\begin{array}{l}\text { Pilot or demonstration project to } \\
\text { improve severe weather forecasting } \\
\text { along barge and railroad transportation } \\
\text { routes (e.g., periods of freezing weather) }\end{array}$ \\
\hline $\begin{array}{l}\text { Reclamation } \\
\text { Vegetation selection determined by weather } \\
\text { and climate } \\
\text { Effects on soil due to precipitation, } \\
\text { wind, humidity, temperature, and solar } \\
\text { radiation }\end{array}$ & $\begin{array}{l}\text { Seasonal precipitation forecasts with } \\
\text { reasonable lead time }\end{array}$ \\
\hline
\end{tabular}

*The content of Table 5 is derived from "Summary Report of the Panel on Climate and the Coal Industry," J. S. Wilson, panel chair, and B. Dethier, rapporteur.

augmented by establishing additional experimental climate forecast centers to improve monthly and seasonal climate forecasts.

Also in accordance with the National Climate Program Act it was recommended that closer contact exist with state climatologists to provide improved service to the energy industry needs. A strong plea was made for continued dialogue between the users and the providers of climate data and information. Establishment of a government-industry liaison committee was also recommended to ensure adequate representation of gas industry needs in the planning development, and use of climatic data bases and predictions.

\section{c. Coal}

There are four primary activities within the coal industry wherein climate information is currently useful: plant siting and permitting, underground and surface coal production, certain modes of transportation of coal from the mine to the end user, and the reclamation of surface mined areas, primar- ily in the West (see Table 5). However, the coal industry, the panel argues, is less significantly affected by climatic conditions than perhaps any of the other energy sectors. The operators, through the pragmatism of experience, have taken into account the vagaries of weather and climate impacts. It is, however, recognized that average temperature on the time scale of days to weeks is of great importance in determining the quantity of coal needed for space heating. But on the other hand, the coal industry maintains a 90-day reserve supply of coal that serves as a significant buffer against climatic impacts. However, extreme or unseasonal periods of low temperature do stress the system by causing freezing of coal piles, frozen rivers blocking barge traffic, and frozen loads of coal in railway cars. It is to be noted that $60 \%$ of coal transportation is by rail; $20 \%$ is by waterways.

The panel noted that monthly or seasonal climate forecasts are being little used by the operators for the reasons stated above; namely, there is a general feeling that reliance upon an unreliable forecast to affect a small saving is unwarranted. 
TABle 6. Summary of findings of the Panel on Climate and the Electric Utilities.*

\begin{tabular}{|c|c|}
\hline List of impacts & $\begin{array}{l}\text { Identification of needs and } \\
\text { recommendations }\end{array}$ \\
\hline $\begin{array}{l}\text { Site selection } \\
\text { Climatic data are required for environmental } \\
\text { assessments }\end{array}$ & $\begin{array}{l}\text { More specific and representative } \\
\text { climate data bases }\end{array}$ \\
\hline \multirow{4}{*}{$\begin{array}{l}\text { Transportation (distribution) } \\
\text { Outages and surges result from } \\
\text { lightning, high winds, severe weather } \\
\text { Broken wires and shorted transformers } \\
\text { result from ice storms }\end{array}$} & Estimates of recurrence frequencies of \\
\hline & extreme events \\
\hline & Climatologies of freezing precipitation \\
\hline & $\begin{array}{l}\text { and lightning (e.g., data pooling by } \\
\text { utilities and government) }\end{array}$ \\
\hline \multirow{3}{*}{$\begin{array}{l}\text { Utilization (average demand) } \\
\text { Air conditioner demand increases in hot } \\
\text { weather } \\
\text { Extended climatic anomalies require } \\
\text { replanning of resources }\end{array}$} & Improved monthly and seasonal forecasts \\
\hline & $\begin{array}{l}\text { Demonstration projects to illustrate } \\
\text { usefulness of forecasts }\end{array}$ \\
\hline & \\
\hline \multirow{2}{*}{$\begin{array}{l}\text { Peaks in demand } \\
\text { Local peaks result from weather extremes, } \\
\text { both hot and cold }\end{array}$} & More specific modeling of given utility's \\
\hline & sensitivity to weather extremes \\
\hline \multirow{2}{*}{$\begin{array}{l}\text { Rate setting } \\
\text { Climatic data are needed to estimate average } \\
\text { electricity use }\end{array}$} & Better tailoring of data to utility \\
\hline & needs \\
\hline
\end{tabular}

*The content of Table 6 is derived from "Summary Report of the Panel on Climate and the Electric Utilities," R. M. Rotty, panel chair, and W. M., Wendland, rapporteur.

Although this panel did not develop recommendations in regard to climate prediction products, some insightful uses of or needs for climate data emerged (see Table 5). Mine operators could, in fact, use high spatial resolution information on the climatology of severe weather phenomena, e.g., extremes on local scale that impact mining operations. Demonstration studies could also be initiated in the use of accurate shortrange predictions for minimizing the freezing of rail car loads. Finally, high resolution climate data are perceived as being useful in the planning and design of the reclamation of surface mined areas in the West, where water requirements and revegetation practices influence the cost and success of these operations.

\section{Electric utilities}

The unique nature of electricity as an energy source (i.e., virtually no storage capability) causes short-term coupling with atmospheric anomalies (see Table 6). One of the most important meteorological impacts upon the electric utility sector arises from power outages caused by lightning, high winds, or severe weather leading to accumulation of ice on wires, causing breakage. Forty to fifty percent of the current service interruptions result from lightning. Prolonged cold and heat waves, of course, also have severe impacts because of the creation of peak loading situations. Rate setting is dependent upon climatic conditions in the service area for which historical data are used as is true for the gas industry. Historical climate data are also used for site selection for generating stations.

As with the previous sectors of the energy industry, recommendations involved enhanced communications, improved data formats, and increased reliability of climate predictions (see Table 6). With respect to climate data, the lack of representativeness was reemphasized, and a plea for the development of climatically homogeneous regions was made.
Since electric utilities are so strongly impacted by special meteorological conditions, such as icing or lightning, it was recommended that an improved climatic data base for these phenomena be established using the data bases of the electric utilities in addition to those of NOAA. It was suggested that the utilities may have more extensive data on these significant phenomenon than the NCDC.

The panel felt that to improve prediction, conditional probability techniques should be employed, particularly for specific locations and parameters. It was further recommended that a study be conducted to determine just how much economic benefit would ensue from improved monthly and seasonal climate forecasts.

\section{Workshop Conclusions}

From the recommendations developed by the four panels, four common themes emerge, each of which needs to be, and can be, addressed as part of a coordinated DOE-NOAAindustry effort.

a. Improved communications. There was unanimous expression from the participants regarding the need for increased quality and frequency of communication between the users and the providers of climate data. Both users and providers perceived positive potential for improved usefulness of information and services under conditions of enhanced communication.

b. Improved climate predictions. The panels echoed, and reechoed, the keynote speaker's perception that it is the extremes of temperature (over weeks, months, or seasons) that most impact or shock energy systems. The prediction of extreme climatic anomalies with increased lead times, prefera- 
bly at least one season in advance, has high priority. In addition, research should be focused both on determining the level of skill of such forecasts that would be useful to the energy industry sectors and on how probabilistic forecasts can best be used. The current monthly and seasonal climate predictions are used little because of the zero lead time and the perception of very limited accuracy. The industry views the lead time question as a vital one and supports focused research on techniques leading to improvement in this regard. Specifically, the oil industry needs to decide in August on the petroleum product mixes that should be used in the fall to meet the expected demands of the next winter season. This requirement implies a lead time of three to four months, which far exceeds the zero lead time of current CAC forecasts.

c. Improvements in quality of climate data. There were several specific suggestions for the improvement of climate data in regard to representativeness of data for the relevant application, high-resolution data oriented towards severe weather climatology at specific sites, and more cooperation between industry and NOAA to merge data from their respective sources to develop data bases of significantly improved quality. Climate information from the federal government could also be improved in format and in kind, perhaps by use of population-weighted or consumption-weighted heating- degree days. All such improvements hinge on more cooperative endeavors and enhanced communications between the users and the providers, as previously noted.

d. Case studies. Case studies and demonstration projects illustrating the potential use of climate information to solve real problems of the energy industry could be most constructive. For instance, the use of high-resolution climate data for the planning and design of reclamation areas of previously surface mined coal is one pertinent example. A second illustration of a demonstration project would be the prediction of extreme temperature conditions warranting remedial measures for the freezing of coal in railroad cars.

The panel reports, the practical suggestions for data improvement, and the recommendations for focused climate research represent the joint effort of the users and the providers of climate and weather information and services to the oil, gas, coal, and electric utility sectors. Also, they represent important collective needs of our nation's energy sector. The workshop determined future opportunities and defined areas of needed research that will contribute to solutions to problems that were clearly identified at this workshop. The goal now must be to pursue these specific approaches to further enhance the efficiency and to provide cost-effective resilience to our nation's energy systems. 
